\title{
Effect of Nordic Walking training on iron metabolism in elderly women
}

This article was published in the following Dove Press journal:

Clinical Interventions in Aging

27 November 2015

Number of times this article has been viewed

\author{
Jakub Kortas' \\ Katarzyna Prusik ${ }^{2}$ \\ Damian Flis ${ }^{3}$ \\ Krzysztof Prusik' \\ Ewa Ziemann ${ }^{4}$ \\ Neil Leaver ${ }^{5}$ \\ Jedrzej Antosiewicz ${ }^{6}$
}

'Department of Recreation and

Tourism, Gdansk University of

Physical Education and Sport, Gdansk,

Poland; ' 2 Department of Biomedical

Basis of Health, Gdansk University of

Physical Education and Sport, Gdansk,

Poland; ${ }^{3}$ Department of Bioenergetics and Physiology of Exercise, Medical

University of Gdansk, Gdansk, Poland;

${ }^{4}$ Department of Physiology and

Pharmacology, Gdansk University of

Physical Education and Sport, Gdansk,

Poland; ${ }^{5}$ The Immunosuppression

monitoring service (IMS) Laboratory,

Royal Brompton \& Harefield NHS

Foundation Trust, Heart Science

Centre, Harefield Hospital, Harefield,

UK; ' ${ }^{6}$ epartment of Biochemistry,

Gdansk University of Physical

Education and Sport, Gdansk, Poland

Correspondence: Jedrzej Antosiewicz Department of Biochemistry, Gdansk University of Physical Education and Sport, Kazimierza Górskiego I, 80-336

Gdansk, Poland

Tel +48585547325

Fax +48 58552075 I

Email jant@gumed.edu.pl
Background: Despite several, well-documented pro-healthy effects of regular physical training, its influence on body iron stores in elderly people remains unknown. At the same time, body iron accumulation is associated with high risk of different morbidities.

Purpose: We hypothesized that Nordic Walking training would result in pro-healthy changes in an elderly group of subjects by reducing body iron stores via shifts in iron metabolismregulating proteins.

Methods: Thirty-seven women aged $67.7 \pm 5.3$ years participated in this study. They underwent 32 weeks of training, 1-hour sessions three times a week, between October 2012 and May 2013. Fitness level, blood morphology, CRP, vitamin D, ferritin, hepcidin, and soluble Hjv were assessed before and after the training.

Results: The training program caused a significant decrease in ferritin, which serves as a good marker of body iron stores. Simultaneously, the physical cardiorespiratory fitness had improved. Furthermore, blood hepcidin was positively correlated with the ferritin concentration after the training. The concentration of blood CRP dropped, but the change was nonsignificant. The applied training resulted in a blood Hjv increase, which was inversely correlated with the vitamin D concentration.

Conclusion: Overall the Nordic Walking training applied in elderly people significantly reduced blood ferritin concentration, which explains the observed decrease in body iron stores.

Keywords: ferritin, hemojuvelin, hepcidin, vitamin D, anti-aging

\section{Introduction}

Iron is an essential element for most of the processes in our body including oxygen transport, cellular reparation, DNA synthesis, and many others. Conversely, iron may be very toxic due to its participation in the formation of reactive oxygen species (ROS). This pro-inflammatory action of iron points to the redox-regulation of the transcription factors' activity such as NF- $\kappa B,{ }^{1,2}$ which controls the expression of more than 500 different gene products, the pro-inflammatory cytokines among them. ${ }^{3}$ Due to its toxicity, iron must be transported and stored in a safe way. In blood, iron is transported by transferrin and stored within cells by ferritin. Both these forms of iron are safe as neither stimulates ROS formation.

Iron induced ROS formation is called labile iron pool (LIP) or chelatable iron loosely bound to amino acids, nucleotides etc. In cells, the elevated LIP leads to an increase in ferritin biosynthesis. Thus, the high cellular ferritin concentrations usually correspond with high iron content. ${ }^{4}$ In addition, ferritin is also considered to be the antioxidant protein, which protects iron from the redox reactions. ${ }^{5}$ It is debatable whether the amount of iron stored correlates with LIP and whether the iron stored is safe. ${ }^{6}$ Evidence exists showing that it is not. For example, blood ferritin concentration correlated with DNA 
damage in humans and animals. ${ }^{7,8}$ Moreover, studies on cell cultures demonstrated that ferritin undergoes degradation releasing iron, when SAPK are active. ${ }^{9,10}$ These data indicate that any procedure which can reduce body iron stores may be beneficial for human health.

Iron metabolism is controlled by hepcidin, a hormone synthetized mainly by the liver. By blocking iron absorption from the duodenum, hepcidin limits its accumulation in the body. ${ }^{11}$ The influence of exercise on iron metabolism had not been fully understood until recently, when skeletal muscles were found to produce and release myokines during exercise, exerting an anti-inflammatory effect and acting as energy sensors. ${ }^{12}$ One of these myokines is IL-6, which up-regulates the anti-inflammatory cytokines such as IL-10, TNF-R, and some others. ${ }^{13}$ Moreover, IL-6 induces biosynthesis and an increase in blood hepcidin concentration. In recent years, studies have demonstrated that both single and regular exercise among adults cause the rise of blood hepcidin, diminishing dietary iron absorption and body iron stores. ${ }^{14,15}$

A study on elderly subjects has demonstrated a relatively high prevalence (12.9\%) of elevated iron stores (serum ferritin $[\mathrm{SF}]>300 \mathrm{ng} / \mathrm{mL}$ in men and $\mathrm{SF}>200 \mathrm{ng} / \mathrm{mL}$ in women). ${ }^{16}$ To our knowledge, no studies so far have investigated the effect of long-lasting Nordic Walking (NW) training on hepcidin concentration in elderly individuals. Moreover, we extended our study to vitamin D status and soluble Hjv (sHjv) evaluation. Vitamin D has been demonstrated to carry an anti-inflammatory activity and its deficiency can lead to an increase in liver iron accumulation. ${ }^{17-19}$ On the other hand, sHjv can affect body iron metabolism by blocking hepcidin biosynthesis. ${ }^{20}$ Consequently, the present study was designed to evaluate the effect of 32 weeks of a regular NW training from two perspectives. First, we evaluated the effect of this popular physical activity on the inflammation response and protein regulating iron metabolism. Second, we assessed if changes induced by applied exercise would be modified by the vitamin D concentration.

\section{Materials and methods Ethics statement}

This study was registered with the Medical University of Gdansk Clinical Trials Registry (ID: NKBBN/523/2013) and approved by the Independent Bioethics Commission for Research of Medical University of Gdansk according to the Helsinki Declaration. Before commencing the training and testing, subjects received a verbal description of the experiment. Written informed consent was signed by all participants. Ethics approval was obtained for the referral of participants to their family physician upon detection of any abnormal pathology results and review by the study medical officer.

\section{Subjects}

Thirty-seven women originally completed this study (67.7 \pm 5.3 years of age, height of $162.5 \pm 5.1 \mathrm{~cm}$, weight of $68.6 \pm 10.0 \mathrm{~kg}$ ) (Figure 1). They were recruited via an advertisement placed in a local newspaper in September 2012. All subjects underwent a medical checkup prior to the experiment. Those with uncontrolled hypertension (diastolic blood pressure over $100 \mathrm{mmHg}$ ), a history of cardiac arrhythmia, cardio-respiratory disorders, and orthopedic problems were excluded from the study $(n=15)$ and six quit the study along the way. The analysis and training program were completed at the Gdansk University of Physical Education and Sport.

\section{Experimental design}

Three months before the main experiment we held a briefing with the volunteers. The aim of this meeting was to introduce the procedure of our experiment and draw attention to the participants' dietary habits focusing on the source of iron in daily nutrition. It was recommended that the volunteers do not change their diet throughout the experiment.

One week prior to the start of the experiment, body composition and aerobic capacity were determined. Body mass and composition were estimated using bioelectrical impedance (TBF-300 Body Fat Monitor/Scale Analyzer, Tanita,

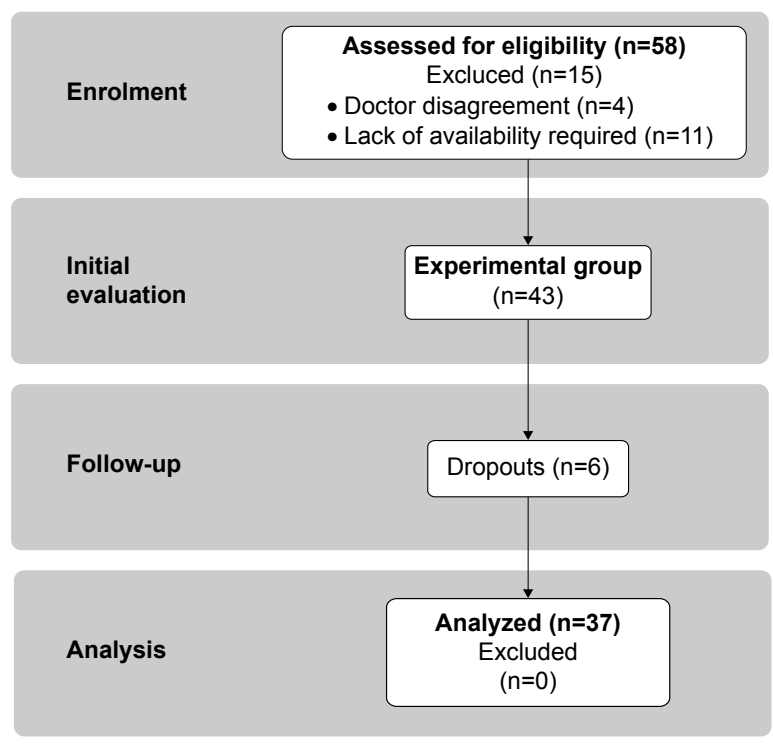

Figure I Consort flow diagram of the study. 
Tokyo, Japan) floor scale with an accuracy of $0.1 \mathrm{~kg}$. The measurements were taken 1 hour before breakfast. Participants had voided their bladders and bowels prior to the assessment. During the measurement, subjects wore only briefs and remained barefoot. The device was calibrated prior to each measurement session. Data accuracy was equal to $98 \% .{ }^{21}$ Additionally, the body mass index was calculated. The exercise test was preceded and followed by a cardiopulmonary function test and blood measurements.

\section{Cardiorespiratory fitness assessment}

The 2,000 $\mathrm{m}$ walking test was used to determine the aerobic capacity of the subjects. ${ }^{22}$ Before the test verbal instruction was given to all participants. The test was performed on an athletic track where the temperature was $18^{\circ} \mathrm{C}$. The test consisted of two stages: first, the reference phase, warm-up (3-minute walk and stretching exercises) and second, the main test of ten laps, each $200 \mathrm{~m}$ long. Time was measured using photoelectric cells (Racetime 2 SF, Microgate, Bolzano, Italy) with an accuracy of 0.001 second. The start of the movement was signaled by the instructor. To evaluate the maximal oxygen capacity a mathematic formula was applied.

$$
\mathrm{VO}_{2 \max }=116,2-2,98 \text { Time-0,11HR-0,14Age-0,39BMI }
$$

\section{NW training intervention}

The physical training lasted 32 weeks between October 2012 and May 2013. Subjects met every Monday, Wednesday, and Friday at 9 am, 1 hour after eating a light breakfast. The same group of research assistants and coaches conducted and supervised all training sessions. Each training sessions lasted 1 hour (10-minute warm-up, 40-minute NW, and 10 -minute cool-down) and had 60\%-70\% intensity of the maximal ability based on a 2,000 m walking test. During the applied training program all of the women covered $299 \mathrm{~km} 600 \mathrm{~m}$ (average $3 \mathrm{~km} 120 \mathrm{~m}$ on the training) of which $92 \mathrm{~km} 400 \mathrm{~m}$ were uphill (average $1 \mathrm{~km} 200 \mathrm{~m}$ on the training), $94 \mathrm{~km} 700 \mathrm{~m}$ were downhill (average $1 \mathrm{~km}$ $90 \mathrm{~m}$ on the training), and $112 \mathrm{~km} 500 \mathrm{~m}$ were flat (average $830 \mathrm{~m}$ on the training).

\section{Blood analysis}

Blood samples were collected at rest, in the morning after an overnight fasting. Next, the subjects were instructed to have a light breakfast. Blood samples were collected at two time points of the experiment: before starting the NW training and after 32 weeks of training. Serum CRP, Hjv, and hepcidin were determined by enzyme immunoassay methods using commercial kits (catalog no DCRP00, SEB979Hu, SEB995Hu). The average intra-assay coefficients of variability (CV) was $<10 \%$ for all assessments. SF was measured by SYSMEX XE 2100, Architect ci 8200, and Test 1 SDL.

\section{Vitamin D determination}

The vitamin D metabolite 25-hydroxy D3 (25OHD3) was measured by high performance liquid chromatography mass spectrometry. The high performance liquid chromatography system was a Transcend TLX turboflow 2 system attached to a TSQ Quantum Ultra triple quadrupole mass spectrometer (Thermo Fisher Scientific, Waltham, MA, USA).

\section{Statistical analysis}

The results were analyzed using Statistica 9.0 software. They are expressed as mean values and standard deviations. The Shapiro-Wilk test was applied to assess the homogeneity of dispersion from the normal distribution. For normally distributed results, a paired $t$-test analysis was performed to identify significantly different results. For not normally distributed results, a Wilcoxon signed-rank test was applied. Relationships between variables were evaluated using a Pearson correlation coefficient. Moreover, coefficient of determination was calculated. The significance level was set at $P<0.05$.

\section{Results General outcomes}

Thirty-seven women completed the study with no adverse events being reported. Attendance at training units was equal to $80 \% \pm 5 \%$. Basic anthropometric and physiological characteristics of the participants are summarized in Table 1. The NW training caused significant changes in body composition. The applied 32-week procedure decreased the body fat content and increased the free fat mass (Table 1). However, the cardiorespiratory fitness capacity did not change following the training period (Table 1).

Hematological parameters were within the reference ranges in all subjects at baseline as well as after the training. Still, a significant drop in hematocrit, hemoglobin $(\mathrm{Hb})$, mean corpuscular $\mathrm{Hb}$ concentration, and mean corpuscular $\mathrm{Hb}$ was observed after the training period (Table 2). Importantly, however, no iron deficiency or anemia was noted.

\section{NW training induced the drop in blood ferritin}

Interestingly, a strong correlation between the body iron stores and blood ferritin was recorded; thus, we aimed to 
Table I Anthropometric and physiological characteristics of participants

\begin{tabular}{|c|c|c|c|c|c|}
\hline \multirow[t]{2}{*}{ Variable } & \multirow[t]{2}{*}{ Pre } & \multirow[t]{2}{*}{ Post } & \multirow[t]{2}{*}{$P$-value } & \multicolumn{2}{|c|}{ Confidence interval } \\
\hline & & & & $-95 \%$ & $+95 \%$ \\
\hline Weight (kg) & $69.4 \pm 10.2$ & $68.6 \pm 10.6^{*}$ & 0.01 & -1.39 & -0.19 \\
\hline Height $(\mathrm{cm})$ & $163.9 \pm 5.9$ & $163.9 \pm 6$ & 0.32 & -0.06 & 0.17 \\
\hline BMI $\left(\mathrm{kg} \cdot \mathrm{m}^{-2}\right)$ & $25.6 \pm 2.9$ & $25.3 \pm 3.1$ & 0.03 & -0.52 & -0.07 \\
\hline Fat $(\mathrm{kg})$ & $23 \pm 6.5$ & $21.7 \pm 6.7^{*}$ & 0.00 & -1.64 & -0.88 \\
\hline Fat (\%) & $33 \pm 6.4$ & $31.4 \pm 6.7^{*}$ & 0.00 & -1.96 & -1.11 \\
\hline FFM (kg) & $45.8 \pm 5.8$ & $46.3 \pm 5.8^{*}$ & 0.03 & 0.06 & 0.88 \\
\hline TBW (kg) & $33.6 \pm 4.2$ & $33.9 \pm 4.2^{*}$ & 0.03 & 0.04 & 0.63 \\
\hline $\mathrm{VO}_{2 \max }\left(\mathrm{mL} \cdot \mathrm{kg}^{-1} \cdot \mathrm{min}^{-1}\right)$ & $29.7 \pm 3.5$ & $30.4 \pm 3.7^{*}$ & 0.00 & 0.34 & 1.09 \\
\hline
\end{tabular}

Notes: Values are means ( \pm standard deviation); Fat, fat mass; Fat \%, percentage of body fat; Pre, measurements at baseline; Post, measurements after 32 weeks of NW training. *Significantly different from Pre.

Abbreviations: BMI, body mass index; FFM, free fat mass; TBW, total body water; $\mathrm{VO}_{2 \text { max }}$, maximal oxygen uptake expressed in relatively values; $\mathrm{NW}$, Nordic Walking.

estimate the effect of the NW training on the blood ferritin concentration. $^{23}$ The obtained data revealed that the blood ferritin concentration had significantly decreased after the 32 weeks of training (Table 3). Therefore, it might be concluded that the NW training had resulted in a significant reduction of the body iron stores.

\section{Changes in blood hepcidin concentration}

Hepcidin is the main regulator of iron metabolism. Its concentration was evaluated, in order to provide insight into the mechanism of the NW training as well as check if the induced drop in the ferritin concentration had depended on the blood hepcidin. Contrary to previous observations, the applied physical training did not trigger significant changes in blood hepcidin. It is important to note that the hepcidin concentration was within reference range. ${ }^{14,24}$

Inflammation is one of the main factors affecting hepcidin biosynthesis; thus, the CRP was measured as a marker for this condition. The applied training procedure induced a drop in CRP; however, the changes were not statistically significant (Table 3). Interestingly, a detailed analysis showed that among 37 women, the applied training resulted in the rise of blood hepcidin in 16 subjects, whereas in the remaining 21 a decrease was noted. Still, the correlation calculated between delta CRP and delta hepcidin recorded after 32 weeks of the NW training was not significant (data not shown). It is important to note that a positive correlation was observed between hepcidin and CRP after the training. In addition to inflammation, stored iron is another factor influencing the hepcidin level. ${ }^{25}$ In fact, following the training procedure blood hepcidin and ferritin were observed to be positively correlated, which is a good marker of body iron stores (Figure 2).

$\mathrm{sHjv}$ is another protein present in blood which may influence hepcidin by inhibiting its biosynthesis. ${ }^{20}$ Thirty-two weeks of the NW training caused the blood sHjv concentration to rise significantly (Table 3 ). Contrary to previous observations, our calculations show that changes in $\mathrm{sHjv}$ did not correlate with changes in hepcidin or CRP (data not shown) ${ }^{26}$

\section{Vitamin D status is not associated with changes in hepcidin}

Aside from the well-documented, anti-inflammatory effect of vitamin $\mathrm{D},{ }^{18,27}$ some changes in iron metabolism were noticed in animals with vitamin D deficiency. ${ }^{17}$ Therefore, the

Table 2 General characteristics of blood tests of participants

\begin{tabular}{|c|c|c|c|c|c|}
\hline \multirow[t]{2}{*}{ Variable } & \multirow[t]{2}{*}{ Pre } & \multirow[t]{2}{*}{ Post } & \multirow[t]{2}{*}{$P$-value } & \multicolumn{2}{|c|}{ Confidence interval } \\
\hline & & & & $-95 \%$ & $+95 \%$ \\
\hline $\mathrm{Hb}\left(\mathrm{g} \cdot \mathrm{dL}^{-1}\right)$ & $\mid 4.2 \pm 1$ & $13.2 \pm 0.9 *$ & 0.00 & -1.37 & -0.63 \\
\hline $\mathrm{MCH}(\mathrm{pg})$ & $31.1 \pm 1.2$ & $29.6 \pm 1.3^{*}$ & 0.00 & -2.01 & -0.96 \\
\hline $\mathrm{MCHC}\left(\mathrm{g} \cdot \mathrm{dL}^{-1}\right)$ & $33.8 \pm 1.6$ & $32.4 \pm 0.6 *$ & 0.00 & -1.96 & -0.85 \\
\hline HCT (\%) & $42.1 \pm 2.6$ & $40.5 \pm 2.6 *$ & 0.00 & -2.58 & -0.51 \\
\hline MCV (fL) & $91.9 \pm 3.5$ & $91.2 \pm 3.6$ & 0.4 & -2.36 & 0.95 \\
\hline $\mathrm{RBC}\left(\min \cdot \mu \mathrm{L}^{-1}\right)$ & $4.6 \pm 0.4$ & $4.5 \pm 0.3$ & 0.06 & -0.29 & 0.01 \\
\hline
\end{tabular}

Notes: Values are means ( \pm standard deviation); Pre, measurements at baseline; Post, measurements after 32 weeks of NW training. *Significantly different from Pre. Abbreviations: $\mathrm{Hb}$, hemoglobin; $\mathrm{MCH}$, mean cell $\mathrm{Hb}$; MCHC, mean corpuscular Hb concentration; $\mathrm{HCT}$, hematocrit; $\mathrm{MCV}$, mean corpuscular volume; RBC, red blood cell. 
Table 3 The effect of 32 weeks of Nordic Walking (NW) training on indicators of iron metabolism among all groups of participants

\begin{tabular}{|c|c|c|c|c|c|}
\hline \multirow[t]{2}{*}{ Variable } & \multirow[t]{2}{*}{ Pre } & \multirow[t]{2}{*}{ Post } & \multirow[t]{2}{*}{$P$-value } & \multicolumn{2}{|c|}{ Confidence interval } \\
\hline & & & & $-95 \%$ & $+95 \%$ \\
\hline Ferritin $\left(\mathrm{ng} \cdot \mathrm{mL}^{-1}\right)$ & $110.2 \pm 82.9$ & $89.1 \pm 66.7^{*}$ & 0.00 & -30.8 & -11.46 \\
\hline CRP (mg. $\left.\mathrm{L}^{-1}\right)$ & $1.9 \pm 1.4$ & $1.6 \pm 1.5$ & 0.06 & -0.6 & 0.12 \\
\hline Hepcidin (ng.mL $\left.L^{-1}\right)$ & $31 \pm 7.9$ & $33.1 \pm 13.8$ & 0.44 & -3.33 & 7.61 \\
\hline Hepcidin $_{\text {corrected }}\left(\mathrm{ng} \cdot \mathrm{mL}^{-1}\right)$ & $35 \pm 11.7$ & $36.1 \pm 14.4$ & 0.72 & -5.11 & 7.34 \\
\hline $\mathrm{sHjv}\left(\mathrm{ng} \cdot \mathrm{mL}^{-1}\right)$ & $768.1 \pm 439.2$ & $1,079.6 \pm 616.3^{*}$ & 0.00 & 130.13 & 492.91 \\
\hline Vitamin D $\left(\mathrm{nmol} \cdot \mathrm{L}^{-1}\right)$ & $62.3 \pm 18.7$ & $58.2 \pm 18.4^{*}$ & 0.00 & -6.76 & -1.37 \\
\hline
\end{tabular}

Notes: Values are means ( \pm standard deviation); Pre, measurements at baseline; Post, measurements after 32 weeks of NW training. *Significantly different to Pre, confidence interval calculated for range of change.

Abbreviation: sHjv, soluble Hjv.

next goal of our study was to evaluate whether the changes observed in the inflammation markers and iron homeostasis were related to changes in the concentration of $25 \mathrm{OHD} 3$ (marker of vitamin D status). As shown in Table 3, a drop in the 25OHD3 concentration was observed after the training; however, the changes did not correlate with changes in CRP $(r=-0.18, P=0.27)$ and hepcidin $(r=-0.21, P=0.22)$. Interestingly, a negative correlation between $\mathrm{SHjv}$ and 25OHD3 was observed after the training $(r=-0.31, P=0.07)$.

\section{Discussion}

In the present study, we demonstrate that 32 weeks of NW training significantly reduced body iron stores in elderly women. To the best of our knowledge, this is the first study reporting such a phenomenon. High iron stores are regarded as a risk factor for morbidities such as cancer, heart disease, neurodegenerative disorders, arteriosclerosis, and many others. ${ }^{28}$ For example, a $1 \%$ rise in blood ferritin increases the risk of heart attack by $4 \%{ }^{29}$ In Finland, men with SF $200 \mathrm{ng} \cdot \mathrm{mL}^{-1}$ or higher had 2.3 times as many heart attacks as men with SF $100 \mathrm{ng} \cdot \mathrm{mL}^{-1}$. Notably, lower blood iron concentration was observed in nonagenarians and centenarians with respect to controls..$^{30}$ In another study regular phlebotomy, which is considered the best way to reduce body iron stores, was shown to reduce cancer incidence by $36.7 \%$ in elderly people. ${ }^{31}$ Consequently, maintaining low body iron stores
A

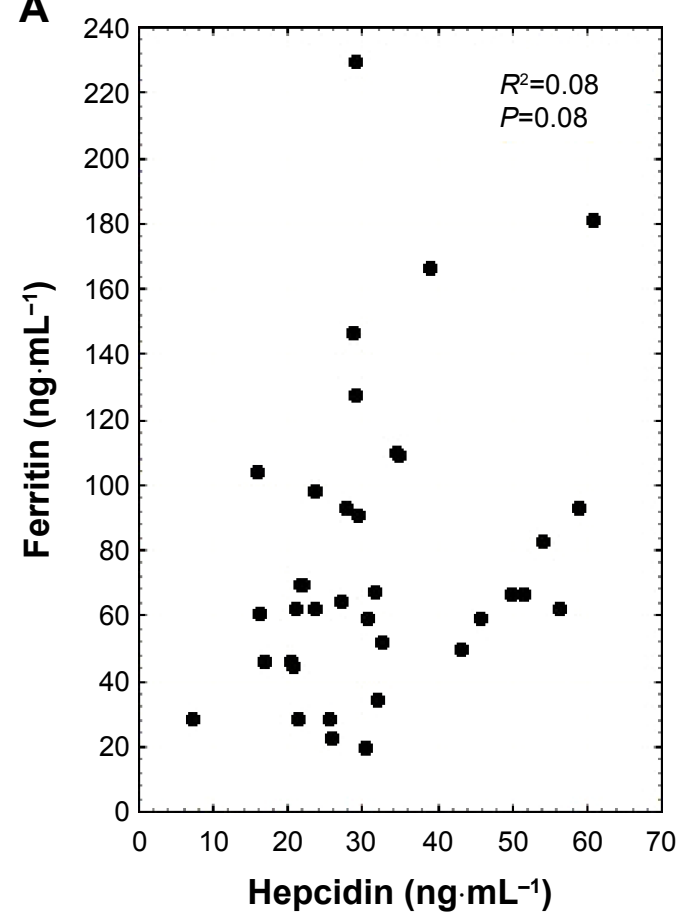

B



Figure 2 Nordic Walking (NW) training induced changes in hormones regulating iron metabolism.

Notes: (A) Blood hepcidin concentration correlates with serum ferritin after 32 weeks of NW training, $n=37$. (B) Blood soluble Hjv concentration negatively correlates with $25 \mathrm{OHD} 3$ in elderly women after 32 weeks of training, $n=37$. 
can be recommended as an effective strategy of decreasing the risk of diseases. Seventy-five percent of new cancer cases have been diagnosed among patients exhibiting mean ferritin levels during follow-up of greater than $57 \mathrm{ng} \cdot \mathrm{mL}^{-1} \cdot{ }^{31}$ Moreover, it was reported that blood ferritin higher than $150 \mathrm{ng} \cdot \mathrm{mL}^{-1}$ correlates negatively with cardiovascular fitness in young men. ${ }^{32}$ Notably, $45.5 \%$ of young men are characterized by ferritin $150 \mathrm{ng} \cdot \mathrm{mL}^{-1}$ or higher. ${ }^{32}$ Our data demonstrate that NW training together with phlebotomy or reduction in iron consumption may constitute supplementary methods of reducing body iron stores. This observation is in agreement with an earlier study which demonstrated that people who spend more leisure time on physical activity are characterized by lower blood ferritin concentration and $\mathrm{Hb}$ content. ${ }^{33}$ The limitation of this study is that there was no control group; however, it is worth noting that iron stores rise slowly with aging. Thus, it can be expected that effect of time could be negligible. ${ }^{34}$ It is important to note that despite the drop observed in $\mathrm{Hb}$, mean corpuscular $\mathrm{Hb}$, and mean corpuscular $\mathrm{Hb}$ concentration, all of these parameters remain in normal physiological ranges. Lower $\mathrm{Hb}$ was previously linked with a lower risk of lung cancer in women ${ }^{35}$ and the prevalence of gestational diabetes mellitus. ${ }^{36}$ In light of these arguments, the observed changes in $\mathrm{Hb}$ should be considered positive.

In many countries, NW is a very popular form of exercise with thousands of enthusiasts. Specially designed poles are used to push against the ground with each stride for the purpose of activating the upper as well as the lower body. NW was shown to increase gait speed and oxygen consumption more effectively than conventional walking. ${ }^{37} \mathrm{NW}$ is also commonly used in rehabilitation of patients with different kinds of morbidities. ${ }^{38,39} \mathrm{NW}$ also has favorable effects on functional capacity in elderly people. ${ }^{40-42}$

To attain insight into the mechanism responsible for NW training induced changes in iron metabolism, hormones controlling the iron status were evaluated. It has recently been shown that single exercise leads to an increase in blood hepcidin; ${ }^{14,25,43}$ thus, we hypothesized that a drop in body iron stores would be accompanied by an elevated level of hepcidin. Its synthesis increases in response to high iron content and inflammatory cytokines whereas its level drops during hypoxia and iron deficiency. Accordingly, our data show that post-training hepcidin concentration positively correlates with blood ferritin. Recently, Peeling et al reported that postexercise hepcidin did not change in subjects whose blood ferritin was $<30 \mathrm{ng} / \mathrm{mL}$ and significantly rose in those with blood ferritin $>30 \mathrm{ng} / \mathrm{mL} .{ }^{25}$ Therefore, we assumed that the effects of training on hepcidin may be dependent on subjects' body iron stores. Interestingly, such correlation was not observed at the beginning of the applied training (Figure 2). Thus, it can be concluded that the NW exercise procedure somehow restored the iron dependent rise in hepcidin.

$\mathrm{Hjv}$ is a glycosylphosphatidyl inositol-linked protein cell membrane. It functions as a BMP co-receptor activating hepcidin expression through a BMP/SMAD signaling pathway. ${ }^{44}$ In addition to residing on the cell membrane, part of Hjv can be cleaved and secreted in a soluble form present in blood. sHjv can selectively bind to BMP ligands and inhibit endogenous and BMP-induced hepcidin expression. Administration of $\mathrm{sHjv}$ decreases hepcidin expression in vivo. ${ }^{20}$ To the best of our knowledge, this is the first report demonstrating the effect of regular training on Hjv. Our data show that sHjv significantly rises after the training program and, contrary to our expectation, positively correlates with the blood hepcidin following the exercise period (data not shown). It can be speculated that the observed rise in blood sHjv is of muscle origin although the biological meaning of these changes is not known. Recent reports showed that systemic iron homeostasis and liver hepcidin expression were not affected in knockout mice, which lack muscle $\mathrm{Hjv} ;{ }^{45}$ thus, it is possible that the observed correlation is random.

Inflammation is another important factor affecting iron metabolism. Pro-inflammatory cytokines were demonstrated to induce $H A M P$ gene expression which encodes hepcidin. ${ }^{46}$ The present study reveals that the NW traininginduced equivocal changes in hepcidin and delta CRP does not correlate with delta hepcidin. However, after the NW training a positive correlation is observed between hepcidin and CRP indicating a role of inflammation in changes in hepcidin. Excess in iron is considered to stimulate inflammation processes as LIP can activate the transcription factor NF-kB, which controls expression of the pro-inflammatory cytokines. ${ }^{47}$ Thus, hepcidin, which impairs iron absorption and in consequence decreases body iron stores, may be considered an anti-inflammatory hormone. Since a positive correlation was noted between blood ferritin and CRP both before and after the applied training, our data support these observations. These data indicate that a decrease in iron stores is associated with a lower grade of systemic inflammation in elderly persons.

Inflammation processes can also be influenced by vitamin D. Different forms of vitamin D were shown to reduce pro-inflammatory signaling. ${ }^{48}$ Our data indicate that NW-induced changes in CRP are not associated with $25 \mathrm{OHD} 3$, a good marker of vitamin D status. It is important 
to note that some subjects had inadequate vitamin $\mathrm{D}$ concentrations of $25 \mathrm{OHD} 3<50 \mathrm{nmolL}^{-1}$. Moreover, a study performed on mice demonstrated that liver iron was increased in vitamin D-depleted animals. ${ }^{17}$ Therefore, the effects of vitamin D status on iron metabolism were expected. Indeed, we observed that a rise in sHjv induced by the NW training negatively correlated with $25 \mathrm{OHD} 3$ concentration. Thus, our data support the notion that vitamin D may have an influence on iron metabolism in humans even if exact biological meaning of this data is not clear.

\section{Conclusion}

In conclusion, our data indicate that the pro-healthy effects of the NW training is manifested by a decreased inflammation and a drop in body iron stores in elderly people. Further investigation is needed to reveal the exact mechanism behind the observed changes.

\section{Acknowledgment}

This investigation was supported by the National Science Centre (Poland), project no 2014/15/B/NZ7/00976.

\section{Disclosure}

The authors report no conflict of interest in this work.

\section{References}

1. Jimenez LA, Thompson J, Brown DA, et al. Activation of NF-kappaB by $\mathrm{PM}(10)$ occurs via an iron-mediated mechanism in the absence of IkappaB degradation. Toxicol Appl Pharmacol. 2000;166(2):101-110.

2. Xiong S, She H, Takeuchi H, et al. Signaling role of intracellular iron in NF-kappaB activation. $J$ Biol Chem. 2003;278(20):17646-17654.

3. Ghosh S, Hayden MS. New regulators of NF-kappaB in inflammation. Nat Rev Immunol. 2008;8(11):837-848.

4. Kruszewski M. Labile iron pool: the main determinant of cellular response to oxidative stress. Mutat Res. 2003;531(1-2):81-92.

5. Konijn AM, Glickstein H, Vaisman B, Meyron-Holtz EG, Slotki IN, Cabantchik ZI. The cellular labile iron pool and intracellular ferritin in K562 cells. Blood. 1999;94(6):2128-2134.

6. Sullivan JL. Is stored iron safe? J Lab Clin Med. 2004;144(6):280-284.

7. Nakano M, Kawanishi Y, Kamohara S, et al. Oxidative DNA damage (8-hydroxydeoxyguanosine) and body iron status: a study on 2507 healthy people. Free Radic Biol Med. 2003;35(7):826-832.

8. Barollo M, D'Inca R, Scarpa M, et al. Effects of iron deprivation or chelation on DNA damage in experimental colitis. Int J Colorectal Dis. 2004;19(5):461-466.

9. Borkowska A, Sielicka-Dudzin A, Herman-Antosiewicz A, Halon M, Wozniak M, Antosiewicz J. P66Shc mediated ferritin degradation - a novel mechanism of ROS formation. Free Radic Biol Med. 2011;51(3): 658-663.

10. Antosiewicz J, Ziolkowski W, Kaczor JJ, Herman-Antosiewicz A. Tumor necrosis factor-alpha-induced reactive oxygen species formation is mediated by JNK1-dependent ferritin degradation and elevation of labile iron pool. Free Radic Biol Med. 2007;43(2):265-270.

11. Ganz T, Nemeth E. Hepcidin and disorders of iron metabolism. Annu Rev Med. 2011;62:347-360.

12. Pedersen BK. Muscles and their myokines. J Exp Biol. 2011;214(Pt 2): $337-346$
13. Pedersen BK. The anti-inflammatory effect of exercise: its role in diabetes and cardiovascular disease control. Essays Biochem. 2006;42:105-117.

14. Antosiewicz J, Kaczor JJ, Kasprowicz K, et al. Repeated "all out" interval exercise causes an increase in serum hepcidin concentration in both trained and untrained men. Cell Immunol. 2013;283(1-2):12-17.

15. Peeling P, Dawson B, Goodman C, Landers G, Trinder D. Athletic induced iron deficiency: new insights into the role of inflammation, cytokines and hormones. Eur J Appl Physiol. 2008;103(4):381-391.

16. Fleming DJ, Jacques PF, Tucker KL, et al. Iron status of the free-living, elderly Framingham Heart Study cohort: an iron-replete population with a high prevalence of elevated iron stores. Am J Clin Nutr. 2001; 73(3):638-646.

17. Otto-Duessel M, Brewer C, Wood JC. Interdependence of cardiac iron and calcium in a murine model of iron overload. Transl Res. 2011;157(2): 92-99.

18. Bednarek-Skublewska A, Smolen A, Jaroszynski A, Zaluska W, Ksiazek A. Effects of vitamin D3 on selected biochemical parameters of nutritional status, inflammation, and cardiovascular disease in patients undergoing long-term hemodialysis. Pol Arch Med Wewn. 2010;120(5): $167-174$.

19. Chen Y, Kong J, Sun T, et al. 1,25-Dihydroxyvitamin D(3) suppresses inflammation-induced expression of plasminogen activator inhibitor-1 by blocking nuclear factor-kappaB activation. Arch Biochem Biophys. 2011;507(2):241-247.

20. Babitt JL, Huang FW, Xia Y, Sidis Y, Andrews NC, Lin HY. Modulation of bone morphogenetic protein signaling in vivo regulates systemic iron balance. J Clin Invest. 2007;117(7):1933-1939.

21. Ziemann E, Grzywacz T, Luszczyk M, Laskowski R, Olek RA, Gibson AL. Aerobic and anaerobic changes with high-intensity interval training in active college-aged men. $J$ Strength Cond Res. 2011;25(4): 1104-1112.

22. Laukkanen RM, Kukkonen-Harjula TK, Oja P, Pasanen ME, Vuori IM. Prediction of change in maximal aerobic power by the 2-km walk test after walking training in middle-aged adults. Int J Sports Med. 2000; 21(2):113-116.

23. Simon TL, Garry PJ, Hooper EM. Iron stores in blood donors. JAMA. 1981;245(20):2038-2043.

24. Kaneko Y, Miyajima H, Piperno A, et al. Measurement of serum hepcidin-25 levels as a potential test for diagnosing hemochromatosis and related disorders. J Gastroenterol. 2010;45(11):1163-1171.

25. Peeling P, Sim M, Badenhorst CE, et al. Iron status and the acute postexercise hepcidin response in athletes. PLoS One. 2014;9(3):e93002.

26. Shalev H, Perez-Avraham G, Kapelushnik J, et al. High levels of soluble serum hemojuvelin in patients with congenital dyserythropoietic anemia type I. Eur J Haematol. 2013;90(1):31-36.

27. Alvarez JA, Zughaier SM, Law J, et al. Effects of high-dose cholecalciferol on serum markers of inflammation and immunity in patients with early chronic kidney disease. Eur J Clin Nutr. 2013;67(3): 267-269.

28. Kell DB. Iron behaving badly: inappropriate iron chelation as a major contributor to the aetiology of vascular and other progressive inflammatory and degenerative diseases. BMC Med Genomics. 2009;2:2.

29. Salonen JT, Nyyssonen K, Korpela H, Tuomilehto J, Seppanen R, Salonen R. High stored iron levels are associated with excess risk of myocardial infarction in eastern Finnish men. Circulation. 1992;86(3): $803-811$.

30. Forte G, Deiana M, Pasella S, et al. Metals in plasma of nonagenarians and centenarians living in a key area of longevity. Exp Gerontol.2014;60: 197-206.

31. Zacharski LR, Chow BK, Howes PS, et al. Decreased cancer risk after iron reduction in patients with peripheral arterial disease: results from a randomized trial. J Natl Cancer Inst. 2008;100(14):996-1002.

32. Mainous AG 3rd, Diaz VA. Relation of serum ferritin level to cardiovascular fitness among young men. Am J Cardiol. 2009;103(1):115-118.

33. Lakka TA, Nyyssonen K, Salonen JT. Higher levels of conditioning leisure time physical activity are associated with reduced levels of stored iron in Finnish men. Am J Epidemiol. 1994;140(2):148-160. 
34. Zacharski LR, Ornstein DL, Woloshin S, Schwartz LM. Association of age, sex, and race with body iron stores in adults: analysis of NHANES III data. Am Heart J. 2000;140(1):98-104.

35. Selby JV, Friedman GD. Epidemiologic evidence of an association between body iron stores and risk of cancer. Int J Cancer. 1988;41(5): $677-682$.

36. Lao TT, Ho LF. Impact of iron deficiency anemia on prevalence of gestational diabetes mellitus. Diabetes Care. 2004;27(3):650-656.

37. Church TS, Earnest CP, Morss GM. Field testing of physiological responses associated with Nordic Walking. Res Q Exerc Sport. 2002; 73(3):296-300.

38. Hanuszkiewicz J, Malicka I, Barczyk-Pawelec K, Wozniewski M. Effects of selected forms of physical activity on body posture in the sagittal plane in women post breast cancer treatment. J Back Musculoskelet Rehabil. 2015;28(1):35-42.

39. Latosik E, Zubrzycki IZ, Ossowski Z, et al. Physiological Responses Associated with Nordic-walking training in Systolic Hypertensive Postmenopausal Women. J Hum Kinet. 2014;43:185-190.

40. Parkatti T, Perttunen J, Wacker P. Improvements in functional capacity from Nordic walking: a randomized-controlled trial among elderly people. J Aging Phys Act. 2012;20(1):93-105.

41. Lapszo J, Giovanis V, Prusik K, Prusik K. Balance control contributors the relationships between leg strength and balance control ability in seniors. Acta Bioeng Biomech. 2012;14(3):3-8.
42. Tschentscher M, Niederseer D, Niebauer J. Health benefits of Nordic walking: a systematic review. Am J Prev Med. 2013;44(1):76-84.

43. Skarpanska-Stejnborn A, Basta P, Trzeciak J, Szczesniak-Pilaczynska L. Effect of intense physical exercise on hepcidin levels and selected parameters of iron metabolism in rowing athletes. Eur J Appl Physiol. 2015;115(2):345-351.

44. Mleczko-Sanecka K, Casanovas G, Ragab A, et al. SMAD7 controls iron metabolism as a potent inhibitor of hepcidin expression. Blood. 2010; 115(13):2657-2665.

45. Chen W, Huang FW, de Renshaw TB, Andrews NC. Skeletal muscle hemojuvelin is dispensable for systemic iron homeostasis. Blood. 2011; 117(23):6319-6325.

46. Andrews NC. Anemia of inflammation: the cytokine-hepcidin link. J Clin Invest. 2004;113(9):1251-1253.

47. Janssen-Heininger YM, Poynter ME, Baeuerle PA. Recent advances towards understanding redox mechanisms in the activation of nuclear factor kappaB. Free Radic Biol Med. 2000;28(9):1317-1327.

48. JanjetovicZ,ZmijewskiMA, Tuckey RC, etal.20-Hydroxycholecalciferol, product of vitamin D3 hydroxylation by $\mathrm{P} 450 \mathrm{scc}$, decreases NF-kappaB activity by increasing IkappaB alpha levels in human keratinocytes. PLoS One. 2009;4(6):e5988.
Clinical Interventions in Aging

\section{Publish your work in this journal}

Clinical Interventions in Aging is an international, peer-reviewed journal focusing on evidence-based reports on the value or lack thereof of treatments intended to prevent or delay the onset of maladaptive correlates of aging in human beings. This journal is indexed on PubMed Central, MedLine,

\section{Dovepress}

CAS, Scopus and the Elsevier Bibliographic databases. The manuscript management system is completely online and includes a very quick and fair peer-review system, which is all easy to use. Visit http://www.dovepress. com/testimonials.php to read real quotes from published authors. 